\title{
Challenges with Present Symptom Control and Risk Reduction of Future Exacerbations in Asthma: Indian Patients' Perspectives
}

Overall, about $4 \%$ of the global population were reported to be suffering from asthma in 2017. ${ }^{[1,2]}$ Its prevalence is increasing and may represent the tip of the iceberg. ${ }^{[3]}$ Even when efficient therapeutic options, national and global guidelines are available, many remain symptomatic. ${ }^{[4,5]}$ As a result, there is increased utility of health-care resources across intensive care, emergency room, and hospital. ${ }^{[6]}$ Multidisciplinary coordinated therapy of any chronic disease can improve the long-term patient outcomes, better health-care professional and personal satisfaction, and reduced cost burden on healthcare. ${ }^{[7]}$ As regards asthma management, interprofessional communication, self-care, and a good patient-physician relationship are promising strategies to reduce symptoms, hospitalization and to improve the overall quality of care.

According to health-care data, problems in the proper treatment of asthma can be related to the patient (lack of trust in the treating physician), to the doctor (lack of time or good infrastructure), and to diagnostic errors (other diseases that may mimic asthma). ${ }^{[8,9]}$ Asthmatics may receive limited multidisciplinary care and there may be a lack of interest among the patients in the care of their disease. Studies should be planned to understand the perception of asthmatic patients regarding self-therapy protocols.

Other than the patients themselves, the main people who have a role in the management of asthma are general practitioners and specialists (pulmonologists, physicians, and intensive care physicians). They have a role in its diagnosis, treatment, follow-up, and patient education. The clinical pharmacist, family physician, and occupational therapists also have a small role in asthma management.

Often neglected in the care of asthmatics is educating the close family members and relatives of the patients about the signs and symptoms, precipitating factors, and immediate therapy. It is important to educate them about some preventive strategies that they can easily understand and supportive measures, they could provide their family members suffering from asthma. In developing countries such as India, majority of the asthmatics do not even know the basic aspects of their disease and tend to be casual or negligent.

Very rarely, a few educated patients understand their illness and become more autonomous in their care. An important factor that determines the relationship between asthmatics and care providers is the severity of the disease and its clinical phase. In the community, the general practitioners act as first responders in patients without severe manifestations, and an emergency physician acts as a first responder if the patient presents with acute severe manifestation such as "status asthmaticus."

Clinical pharmacists, respiratory therapists, and physiotherapists are other caregivers and involved in patient education. When the patient is severely ill and admitted to the intensive care unit (ICU) for mechanical ventilation and other organ support, an intensivist plays a significant role during the phase of weaning from the ICU care. The ICU team can have a significant impact on the patients' self-esteem, understanding of self-care, and immediate troubleshooting. Overall patients' behavior reflects the therapy he has received for asthma at different stages. In developing countries, many patients were unaware and uncertain about the diagnosis of asthma for a long time. Spirometry may not always help in diagnosis, prognosis, and follow-up. ${ }^{[10]}$

Many rural, uneducated, and low socio-economic category patients get consultation only during acute exacerbation of symptoms and tend to discontinue long-term care and follow-up in the symptom-free periods. ${ }^{[11]}$ This discontinuous care leads to a lack of awareness about self-care and results in poor long-term outcomes.

A physician and patient-integrated approach are very important to asthma therapy, wherein knowledge of self-care and follow-up is an important aspect. In India, some self-care educational activities may be seen in some private or public sector hospitals, however, patients rarely access such programs. Self-management programs may not be successful unless the media gets involved in creating this awareness.

Despite the proven benefit of reducing emergency care, hospitalization and improving the overall quality of life, ${ }^{[12]}$ the nonavailability of protocols for patient care pathways lead to lacunae in the diagnosis and timely treatment of needy patients. Lack of proper communication between individuals can escalate the problem, poor control of disease, and impact patient's economic and social growth.

Many patients in developing countries prefer oral medications as compared to inhalational therapy. ${ }^{[13]}$ Evidence suggests the compliance with inhalers and inhaled medications is very poor. ${ }^{[14,15]}$ Some patients, even when they have inhaler and inhaled medications, were not able to use it in an optimal way to have maximum benefit. This demonstrated the lacunae from health-care providers in motivating and educating the patients appropriately. Other factors which hinder their use may be 
Harish and Ramya: Challenges with present symptom control and risk reduction of future exacerbations in asthma: indian patient's perspectives

simple forgetfulness or possibly, cultural beliefs that these devices are unsafe, addictive, difficult to use. ${ }^{[16]}$

In conclusion, an in-depth knowledge should be provided to the asthma patients in relation to their severity of illness, nature of medications, comorbidities, and troubleshooting during exacerbations, explained to them in their own language to encourage self-care and improve the long-term outcomes.

M. M. Harish, B. M. Ramya'

Departments of Critical Care Medicine and ${ }^{1}$ Anaesthesia, Mazumdar Shaw Medical Center, Narayana Hrudayalaya, Bengaluru, Karnataka, India

Address for correspondence: Dr. M. M. Harish, Department of Critical Care Medicine, Mazumdar Shaw Medical Center, Narayana Hrudayalaya, Bengaluru - 560 099, Karnataka, India. E-mail: dr.harishmm@rocketmail.com

\section{RefERENCES}

1. World Health Organization. Asthma, Key Facts. World Health Organization; 2017.

2. Afrite A, Allonier C, Laure Com-Ruelle, Nelly Le Guen, Isabella AnnesiMaesano, Marie-Christine. Asthma in France in 2006: Prevalence and control of symptoms. QES 2008;138:1-8.

3. Van Schayck CP, van der Heijden FM, van den Boom G, Titimanna PR, van Herwaarden CL. Underdiagnosis of asthma: Is the doctor or the patient to blame? The DIMCA project. Thorax 2000;55:562-5.

4. Price D, Fletcher M, van der Molen T. Asthma control and management in 8,000 European patients: The recognise asthma and link to symptoms and experience (REALISE) survey. NPJ Prim Care Respir Med 2014;24:14009.

5. Raherison C, Mayran P, Jeziorski A, Deccache A, Didier A. Patients with asthma: Disease control, patients' perceptions and observance. Results of the French REALISE survey. Rev Mal Respir 2017;34:19-28.

6. Bahadori K, Doyle-Waters MM, Marra C, Lynd L, Alasaly K, Swiston J, et al. Economic burden of asthma: A systematic review. BMC Pulm Med 2009;9:24.

7. Coleman K, Austin BT, Brach C, Wagner EH. Evidence on the chronic care model in the new millennium. Health Aff (Millwood) 2009;28:75-85.

8. Roberts NJ, Younis I, Kidd L, Partridge MR. Barriers to the implementation of self-management support in long term lung conditions. London J Prim Care (Abingdon) 2013;5:35-47.

9. Dennis SM, Zwar NA, Marks GB. Diagnosing asthma in adults in primarycare: A qualitative study of Australian GPs' experiences. Prim Care Respir J 2009; 19:52-6.

10. Rabe KF, Vermeire PA, Soriano JB, Maier WC. Clinical management of asthma in 1999: The asthma insights and reality in Europe (AIRE) study. Eur Respir J 2000;16:802-7.

11. Vermeire PA, Rabe KF, Soriano JB, Maier WC. Asthma control and differences in management practices across seven European countries. Respir Med 2002;96:142-9.

12. Pinnock H, Parke HL, Panagioti M, Daines L, Pearce G, Epiphaniou E, et al. Systematic meta-review of supported self-management for asthma: A healthcare perspective. BMC Med 2017;15:64.

13. Sodhi R, Prasad R, Kushwaha RA, Kant S, Verma SK, Garg R, et al. A study to know the knowledge, attitude, and practices of patients of bronchial asthma. Int J Med Public Health 2013;3:159-62.

14. Bhattacharyya P, Paul R, Nag S, Bardhan S, Saha I, Ghosh M, et al. Treatment of asthma: Identification of the practice behavior and the deviation from the guideline recommendations. Lung India 2010;27:141-4.

15. Pandey A, Tripathi P, Pandey RD. Prescription pattern in asthma therapy at Gorakhpur hospitals. Lung India 2010;27:8-10.

16. Gupta PP, Gupta KB. Awareness about the disease in asthma patients receiving treatment from physicians at different levels. Indian J Chest Dis Allied Sci 2001;43:91-5.

This is an open access journal, and articles are distributed under the terms of the Creative Commons Attribution-NonCommercial-ShareAlike 4.0 License, which allows others to remix, tweak, and build upon the work non-commercially, as long as appropriate credit is given and the new creations are licensed under the identical terms.

\begin{tabular}{|l|l|}
\hline \multicolumn{3}{|c|}{ Access this article online } \\
\hline Quick Response Code: & Website: \\
& www.ijrconline.org \\
& \\
&
\end{tabular}

How to cite this article: Harish MM, Ramya BM. Challenges with present symptom control and risk reduction of future exacerbations in asthma: Indian patients' perspectives. Indian J Respir Care 2020;9:129-30.

Received: 13-12-2019 Revised: 29-01-2020

Accepted: 25-02-2020 Published: 05-06-2020 